\title{
Copper Binding in Sweet Worts Made from Specialty Malts
}

Marcus Pagenstecher ${ }^{1}$, Irina Bolat ${ }^{3}$, Morten J. Bjerrum², Mogens L. Andersen*1

${ }^{1}$ Department of Food Science, University of Copenhagen. ${ }^{2}$ Department of Chemistry, University of Copenhagen, Copenhagen Denmark. ${ }^{3}$ Boortmalt International.

*To whom correspondence should be addressed: Department of Food Science, University of Copenhagen, Rolighedsvej 26, DK-1958 Frederiksberg, Tel: +4535333262 


\section{Supporting Information}

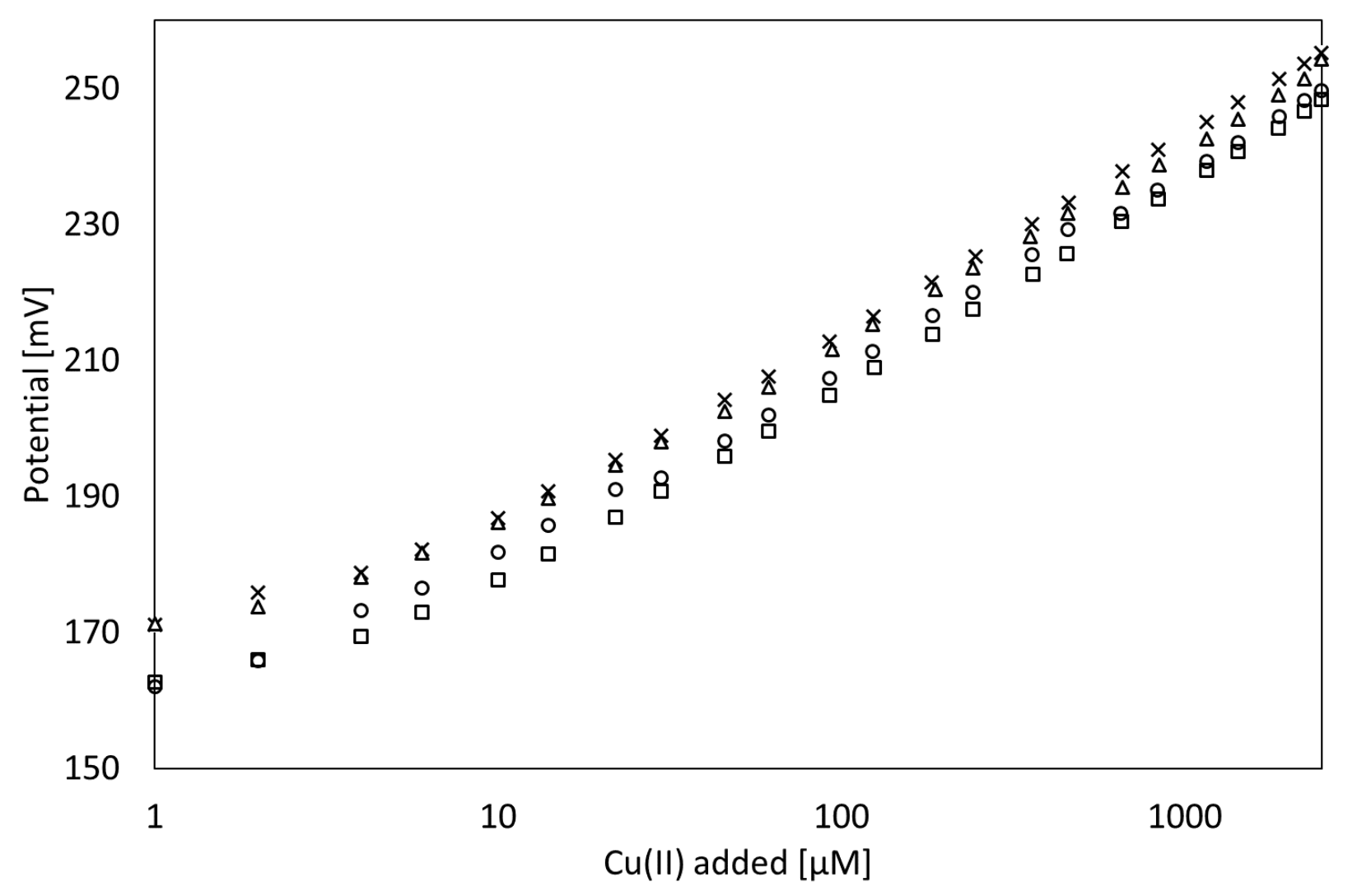

Figure S1. Standard curves obtained by potentiometric titration of $\mathrm{Cu}\left(\mathrm{NO}_{3}\right)_{2}$ into $100 \mathrm{mM} \mathrm{KNO} \mathrm{K}_{3}$ to account for small changes in the behavior of the ISE over time. Linear regressions of the logarithmic plots only included data points above $10^{-5} \mathrm{M} \mathrm{Cu}(\mathrm{II})$ added, but linear correlations can be assumed down to $10^{-8} \mathrm{M}$ based on the study by Somavarapu et al. ${ }^{1}$ Pilsner and roasted malt worts $\left(\mathbf{x}\right.$; slope $\left.=28.8 \mathrm{mV} / \log C_{\text {cui }} ; \mathrm{R}^{2}=0.9994\right)$, worts made from a mix of pilsner and roast malt $\left(\square ; 29.6 \mathrm{mV} / \log \mathrm{C}_{\mathrm{cu}} ; 0.9998\right)$, worts with adjusted pH $(\Delta ; 28.2$ $\left.\mathrm{mV} / \log \mathrm{C}_{\mathrm{Cu}} ; 0.9990\right)$, and caramel malt worts $\left(0 ; 28.6 \mathrm{mV} / \log \mathrm{C}_{\mathrm{Cu}} ; 0.9986\right) . \mathrm{C}_{\mathrm{Cu}}$ is concentration of added $\mathrm{Cu}(\mathrm{II})$. 


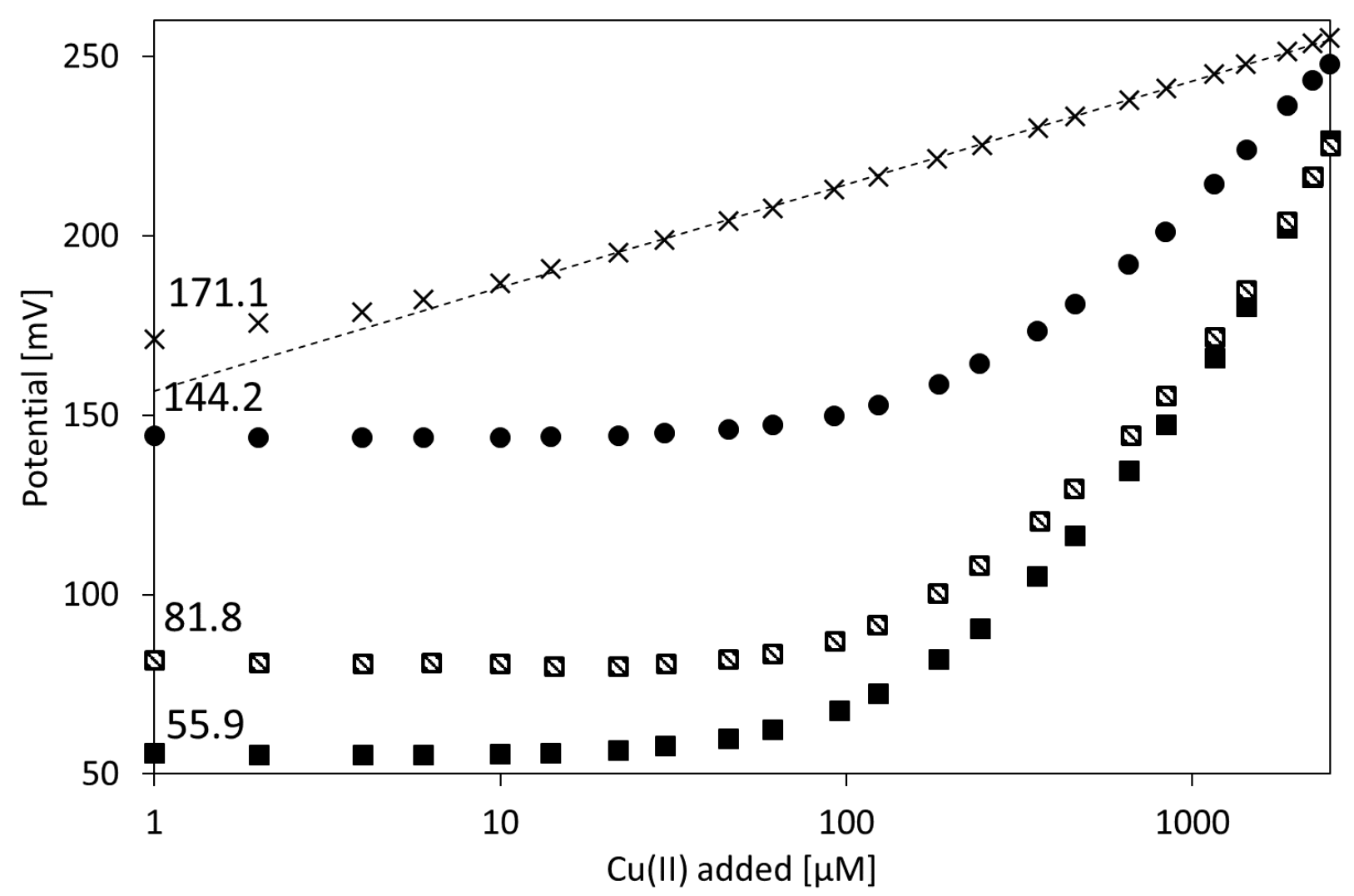

Figure S2. ISE potentials of $\mathrm{Cu}\left(\mathrm{NO}_{3}\right)_{2}$ titrations of $\mathrm{EBC}$ congress worts made from Pilsner malt ( $\left.\mathbf{\square}\right)$, malt roasted at $190^{\circ} \mathrm{C}(\bullet)$, and a mixture of $80 \%$ Pilsner and $20 \%$ roasted malt $(\mathbb{\mathbb { V }})$. 


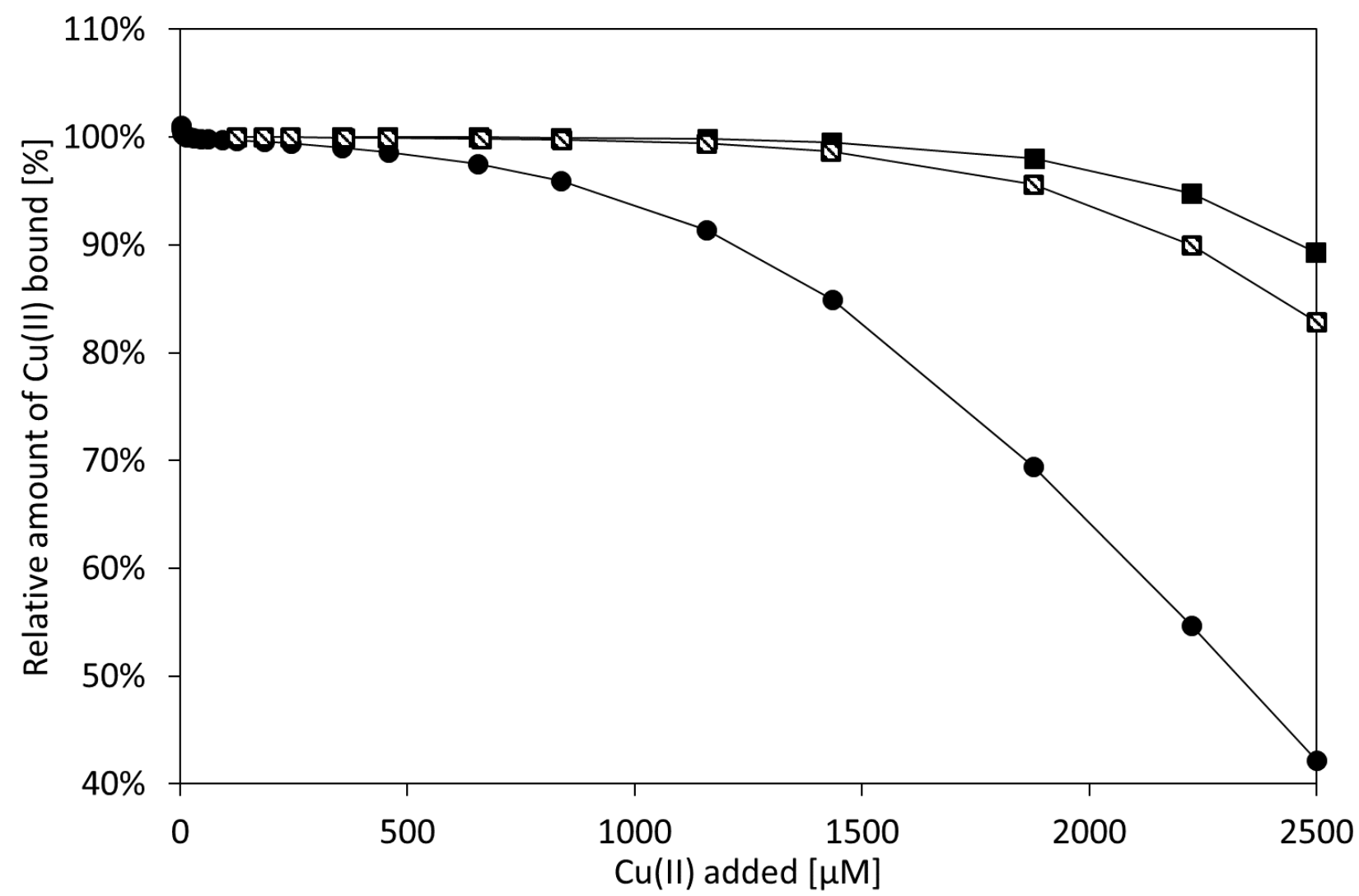

Figure S3. Relative amounts of added $\mathrm{Cu}(\mathrm{II})$ bound during $\mathrm{Cu}\left(\mathrm{NO}_{3}\right)_{2}$ titrations of $\mathrm{EBC}$ congress worts made from Pilsner malt $(\square)$, malt roasted at $190^{\circ} \mathrm{C}(\bullet)$, and a mixture of $80 \%$ Pilsner and $20 \%$ roasted malt $(\mathbb{\otimes})$. Data points with free $\mathrm{Cu}^{2+}(a q)$ concentrations below $10^{-8} \mathrm{M}$ are not included in the figure. 


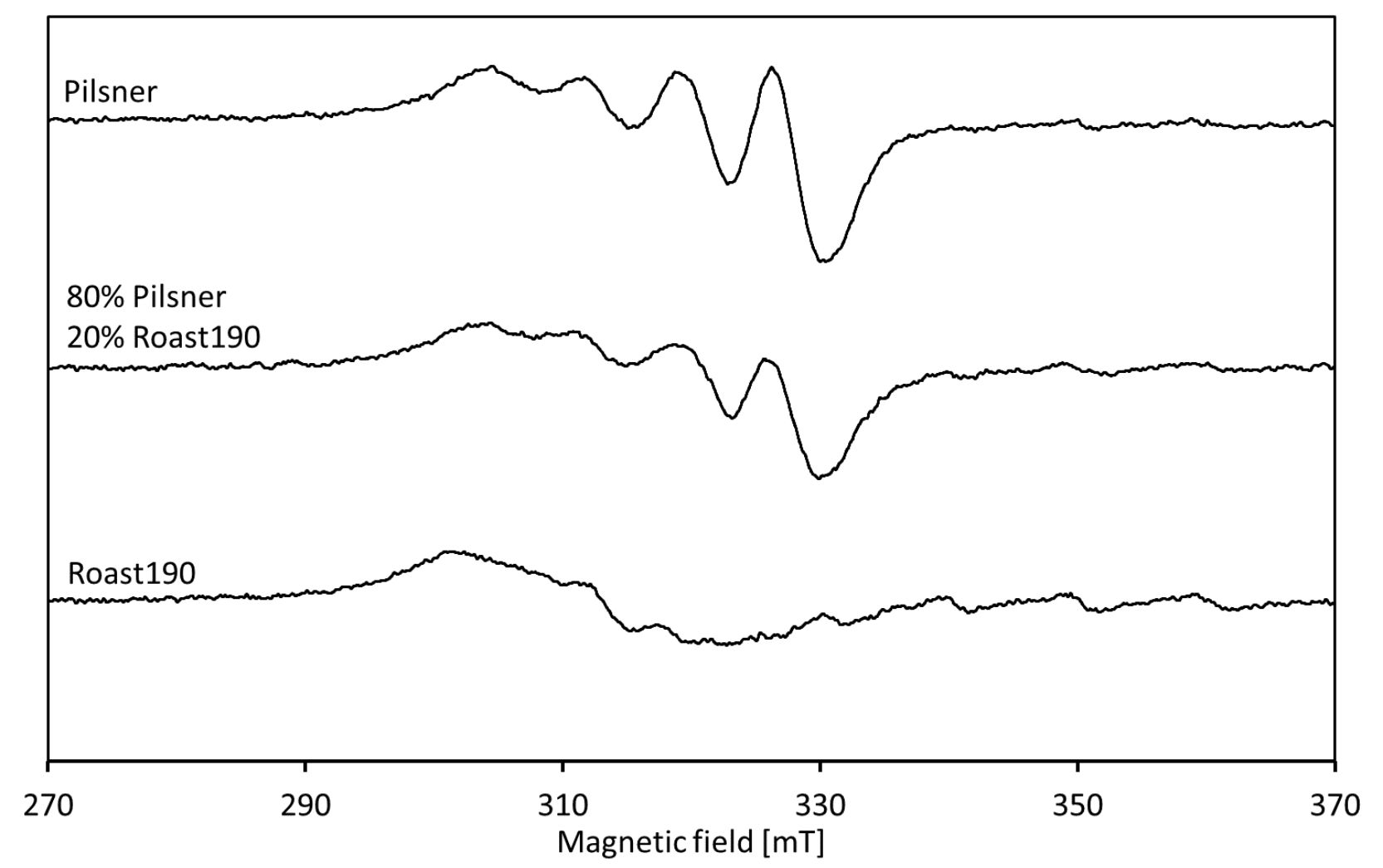

Figure S4. EPR spectra of worts made from Set I Pilsner malt and the same malt roasted at $190^{\circ} \mathrm{C}$ as well as a mixture of the two, with addition of $\mathrm{Cu}\left(\mathrm{NO}_{3}\right)_{2}$ to a final concentration of $1 \mathrm{mM}$. 


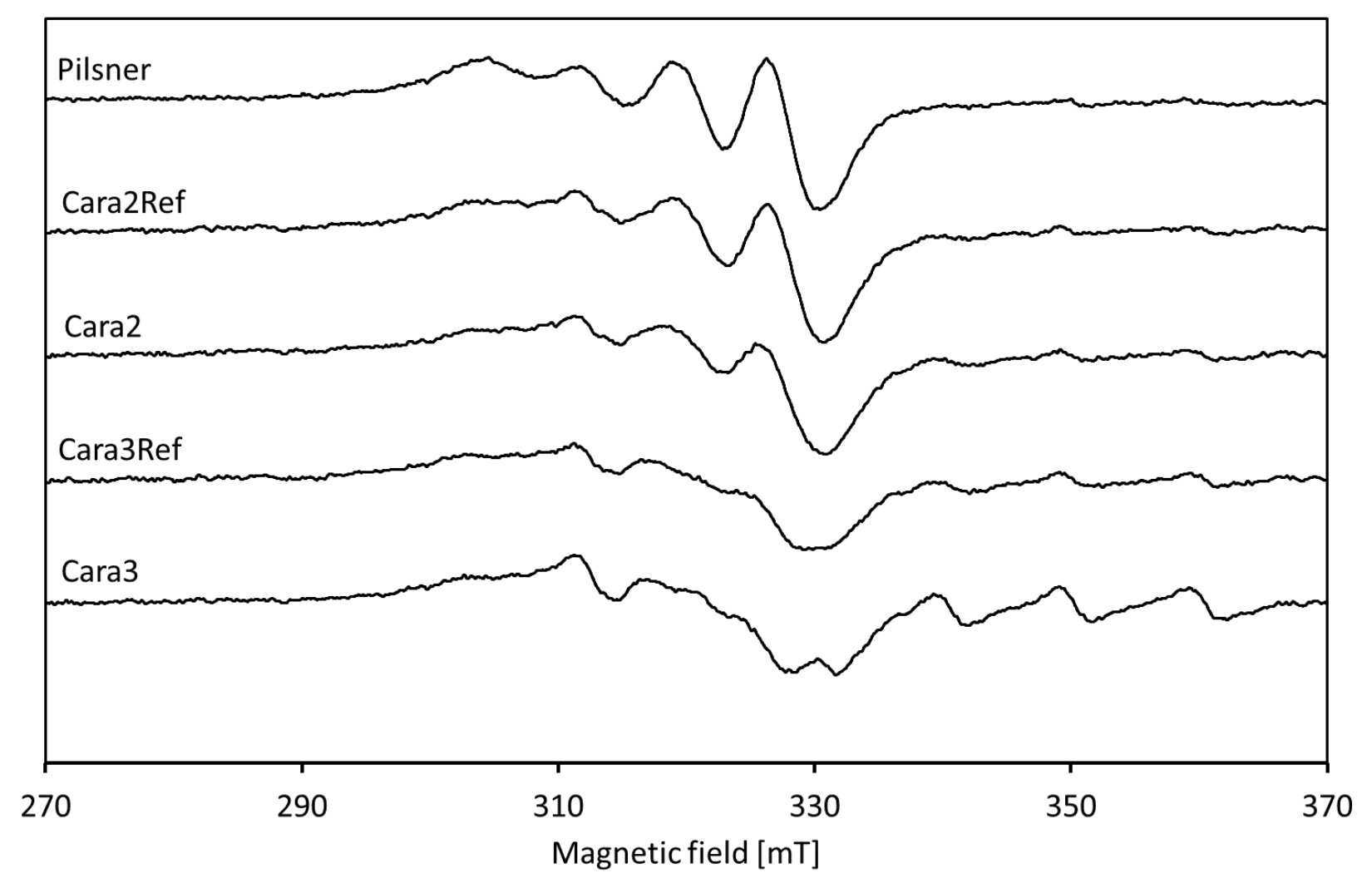

Figure S5. EPR Spectra of Pilsner wort (Set I) and the worts made from isothermally kilned caramel malt of Set II, including their unstewed references with addition of $1 \mathrm{mM} \mathrm{Cu}\left(\mathrm{NO}_{3}\right)_{2}$. 


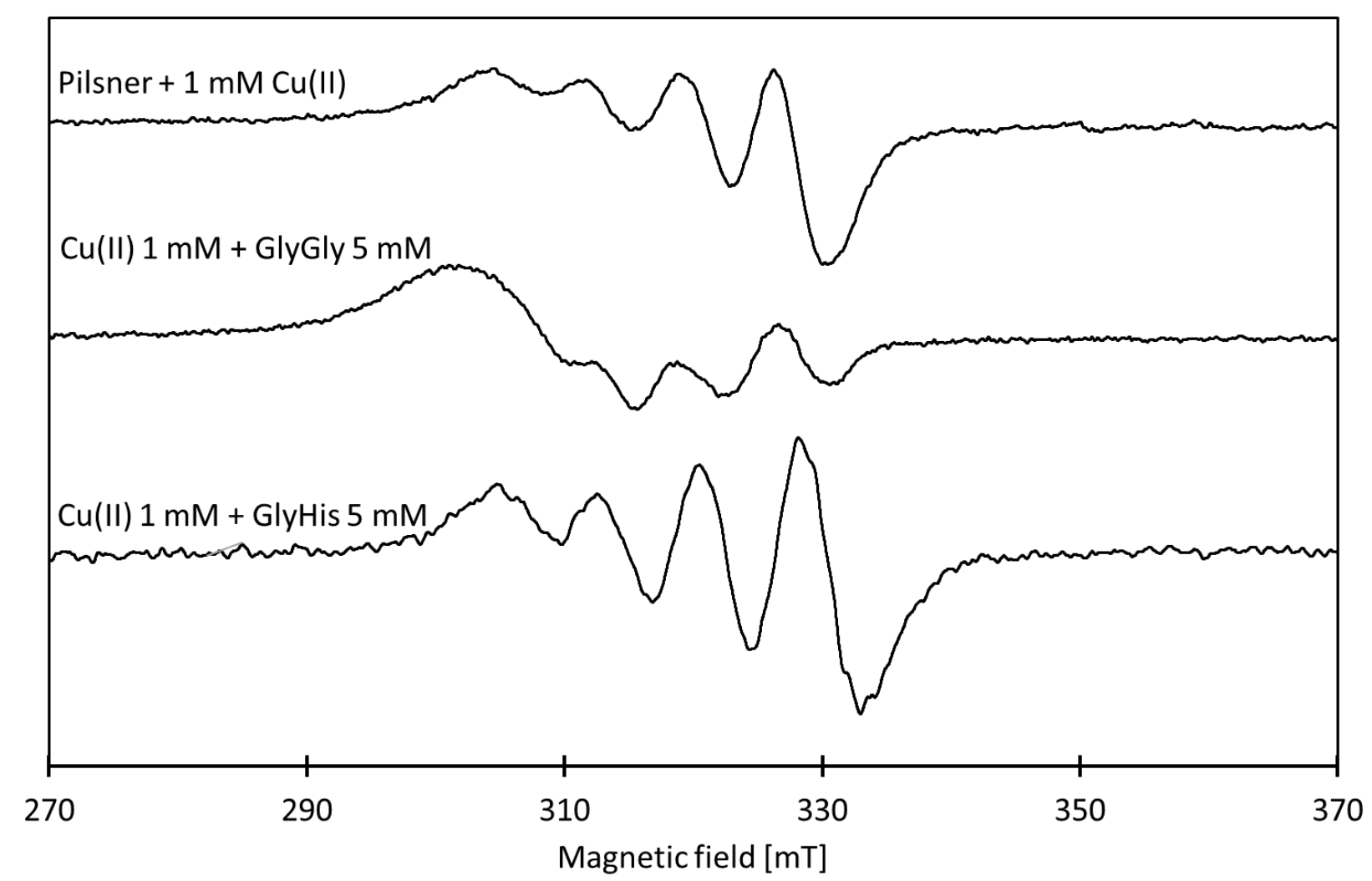

Figure S6. EPR Spectra of Pilsner wort, GlyGly $(5 \mathrm{mM})$ and GlyHis $(5 \mathrm{mM})$ with additon of $1 \mathrm{mM} \mathrm{Cu}\left(\mathrm{NO}_{3}\right)_{2}$. 


\section{References}

(1) Somavarapu, A. K.; Shen, F.; Teilum, K.; Zhang, J.; Mossin, S.; Thulstrup, P. W.; Bjerrum, M. J.; Tiwari, M. K.; Szunyogh, D.; Søtofte, P. M.; et al. The Pathogenic A2V Mutant Exhibits Distinct Aggregation Kinetics, Metal Site Structure, and Metal Exchange of the $\mathrm{Cu}^{2+}-\mathrm{A} \beta$ Complex. Chem. - A Eur. J. 2017, 23 (55), 13591-13595. https://doi.org/10.1002/chem.201703440. 